Check for updates

Cite this: RSC Adv., 2018, 8, 33845

Received 27th June 2018

Accepted 21st September 2018

DOI: $10.1039 / c 8 r a 05504 a$

rsc.li/rsc-advances

\section{Variation in the main health-promoting compounds and antioxidant activity of whole and individual edible parts of baby mustard (Brassica juncea var. gemmifera)}

\author{
Bo Sun, (D) † Yu-Xiao Tian, $\dagger$ Min Jiang, Qiao Yuan, Qing Chen, Yong Zhang, Ya Luo, \\ Fen Zhang* and Hao-Ru Tang (D) *
}

\begin{abstract}
Despite being a brassicaceous vegetable that is widely consumed in winter and spring in Southwest China, there is lack of information available on baby mustard. The aim of this study was to determine the contents of soluble proteins, soluble sugars, chlorophylls, carotenoids, ascorbic acid, proanthocyanidins, flavonoids, total phenolics, and glucosinolates, as well as the antioxidant activity of the whole edible parts and seven individual edible parts (swollen stem: petioles, peel, flesh; lateral bud: leaves, petioles, peel, flesh) of baby mustard. The results showed that significant differences in healthpromoting compounds and antioxidant activity existed between the different edible parts. The lateral bud of baby mustard possessed greater health-promoting compounds than the swollen stem. In particular, the lateral bud leaves possessed abundant antioxidant compounds and antioxidant activity, indicating that these should be conserved during harvesting due to their potential contribution to human health. Furthermore, aliphatic glucosinolates were predominant, and sinigrin was the most abundant glucosinolate in all the assessed parts of baby mustard, the content of which was $15.81 \mu \mathrm{mol}$ $\mathrm{g}^{-1}$ dry weight, accounting for more than $87 \%$ of the total glucosinolate content. However, the sinigrin content in baby mustard is lower than tuber mustard, which explains the less pungent flavor of baby mustard and its better suitability as a fresh vegetable. In addition, antioxidant activity was highly correlated with total phenolics, whereas gluconasturtiin and soluble sugars were negatively correlated with the majority of antioxidants.
\end{abstract}

\section{Introduction}

The concentration and composition of glucosinolates, which constitute important secondary metabolites of brassicaceous plants, ${ }^{1}$ are influenced by many environmental factors and also vary greatly between different tissues within the same plant. ${ }^{2,3}$ By mid-2014, more than 130 different glucosinolates had been identified. ${ }^{4}$ Based on the structure of different amino acid precursors, glucosinolates can be grouped into three classes, namely aliphatic, with a methionine precursor; indole, with a tryptophan precursor; and aromatic, with an aromatic amino acid precursor. ${ }^{5}$ It is widely recognized that glucosinolates and their breakdown products all exhibit strong biological activity. When cruciferous plant tissues suffer mechanical damage, glucosinolates will react with myrosinase to destabilize isothiocyanates, ${ }^{6}$ which has also been shown to be effective in reducing the risk of cancer, particularly bladder, colon, and

College of Horticulture, Sichuan Agricultural University, Chengdu 611130, China. E-mail:zhangf_12@163.com; htang@sicau.edu.cn

$\dagger$ These authors contributed equally to this work. lung cancer. ${ }^{7-9}$ In addition to glucosinolates, Brassica vegetables also contain many health-promoting compounds, including ascorbic acid, carotenoids, and various phenolics. ${ }^{10-13}$

The cruciferous vegetable baby mustard (Brassica juncea var. gemmifera) is a popular vegetable that is grown in the moist climate of Southwest China. It is a variant of stem mustard that was discovered in China in 1985 and is eaten in the winter and spring seasons when fewer fresh vegetables are available. ${ }^{14}$ It is tender with a sweet and fragrant flavor and can be eaten raw, cooked, or pickled. ${ }^{15}$ There are a few varieties of baby mustard, and 'Linjiang-Ercai' is the primary variety consumed in Southwest China. Vegetables are indispensable to the human diet and are valued for their nutritional properties. A number of studies are available on various Brassica vegetables; however, there have been far fewer studies on baby mustard, and even fewer regarding the nutritional composition of the individual edible parts. The objective of this study was thus to determine the content and composition of the main health-promoting compounds and the antioxidant activities in the whole and individual edible parts of baby mustard. These findings will provide a guideline for the human diet. 


\section{Experimental}

\section{Plant material and cultivation}

Baby mustard plants were grown in an open field at an experimental base located at the Sichuan Agricultural University, China $\left(29^{\circ} 58^{\prime} 54.23^{\prime \prime} \mathrm{N} ; 102^{\circ} 59^{\prime} 57.54^{\prime \prime} \mathrm{E}\right)$ on September $2^{\text {nd }}, 2016$, and were harvested on December $25^{\text {th }}, 2016$. The cultivar of this experimental material is 'Linjiang-Ercai', which is the main cultivar in China. Five baby mustard plants were divided into one group as a repeat, and four repeats were used in this experiment. After harvesting, whole edible parts of baby mustard (Fig. 1A) exhibiting similar growth tendencies were transported to the laboratory immediately and divided into seven individual parts according to their morphological and botanical difference, including swollen stem petioles, swollen stem peel, swollen stem flesh, lateral bud leaves, lateral bud petioles, lateral bud peel, and lateral bud flesh. The whole edible parts of baby mustard also constituted a sample (Fig. 1B). The samples were then lyophilized in a freeze-dryer and stored at $-20{ }^{\circ} \mathrm{C}$ until further analysis.

\section{Quality assessment}

Glucosinolate composition and content. Glucosinolates were extracted and analyzed as previously described. ${ }^{\mathbf{1 6 , 1 7}}$ Freeze-dried samples $(100 \mathrm{mg})$ were boiled in $5 \mathrm{~mL}$ water for $10 \mathrm{~min}$. The supernatant was collected after centrifugation (5 min, 4000g), and the residues were washed once with water $(5 \mathrm{~mL})$, centrifuged and then combined with the previous extract. The aqueous extract was applied to a DEAE-Sephadex A-25 (40 $\mathrm{mg})$ column (pyridine acetate form) (GE Healthcare, Piscataway, NJ). The glucosinolates were converted into their desulpho analogues by overnight treatment with $100 \mu \mathrm{L}$ of $0.1 \%$ (1.4 units) aryl sulphatase (Sigma), and the desulphoglucosinolates were eluted with 2 $\times 0.5 \mathrm{~mL}$ water. HPLC analysis of desulphoglucosinolates was carried out using a Waters High-performance Liquid Chromatography (HPLC) instrument equipped with a Model 2996 PDA absorbance detector (Waters, USA). Samples $(20 \mu \mathrm{L})$ were separated at $30^{\circ} \mathrm{C}$ on a Waters Spherisorb C18 column $(250 \times 4.6 \mathrm{~mm}$ i.d.; $5 \mu \mathrm{m}$ particle size) using acetonitrile and water at a flow rate of $1.0 \mathrm{~mL} \mathrm{~min}^{-1}$. Absorbance was detected at $226 \mathrm{~nm}$. ortho-
Nitrophenyl- $\beta$-D-galactopyranoside (Sigma) was used as an internal standard for HPLC analysis.

Soluble protein content. The soluble protein content was determined using the method of Bradford. ${ }^{18}$ Fifty milligrams of freeze-dried powdered material was soaked in $10 \mathrm{~mL}$ of distilled water. The solution was stirred for $30 \mathrm{~s}$ using a vortex mixer, after which it was allowed to settle for $30 \mathrm{~min}$. The solution was then centrifuged for $5 \mathrm{~min}$ at $4000 \mathrm{~g}$ and $1 \mathrm{~mL}$ transferred to a polypropylene tube. Subsequently, Coomassie brilliant blue G250 was combined with $1 \mathrm{~mL}$ of supernatant. The absorbance was measured at $595 \mathrm{~nm}$ within $20 \mathrm{~min}$ after the reaction. Soluble proteins in the samples were calculated based on a standard curve of bovine serum albumin.

Soluble sugar content. The determination of soluble sugar content was performed using the method proposed by Morris. ${ }^{19}$ Fifty milligrams of powder was extracted in $10 \mathrm{~mL}$ of distilled water for $20 \mathrm{~min}$ at $90{ }^{\circ} \mathrm{C}$, following which the homogenates were centrifuged at $4000 \mathrm{~g}$ for $5 \mathrm{~min}$. A combination of $1 \mathrm{~mL}$ of sample extract, $0.5 \mathrm{~mL}$ anthrone-ethyl acetate reagent, and $5 \mathrm{~mL}$ concentrated sulfuric acid was homogenized and boiled for $5 \mathrm{~min}$, and then cooled rapidly using ice water. The absorbance of the reaction mixtures was measured at $630 \mathrm{~nm}$ using a spectrophotometer, and the soluble sugar content was determined using a standard curve of sucrose.

Chlorophyll content. Fifty mg powder of lateral bud leaves and $300 \mathrm{mg}$ of other samples were ground and extracted with $10 \mathrm{~mL}$ ethanol, centrifuged at $4000 \mathrm{~g}$ at room temperature for $5 \mathrm{~min}$, respectively. The supernatant was collected and total chlorophyll content was measured by reading the absorbance at $665 \mathrm{~nm}$ and $649 \mathrm{~nm}$ with a spectrophotometer. Chlorophyll contents were expressed as $\mathrm{mg} \mathrm{kg}^{-1}$ dry weight. ${ }^{13}$

Total carotenoid content. Fifty mg of powder was extracted with $10 \mathrm{~mL}$ of a mixture of acetone and petroleum ether $(1: 1, \mathrm{v} /$ $\mathrm{v})$, total carotenoid content was measured by reading the absorbance at $451 \mathrm{~nm}$ with spectrophotometer. Total carotenoid contents were expressed as $\mathrm{mg} \mathrm{kg}^{-1}$ dry weight. ${ }^{13}$

Ascorbic acid content. Ascorbic acid content was determined using the methods of Sun et al. ${ }^{13}$ Fifty $\mathrm{mg}$ of sample powder was extracted with $5 \mathrm{~mL} 1.0 \%$ (w/v) oxalic acid, subsequently centrifuged $5 \mathrm{~min}$ at $4000 \mathrm{~g}$. Each sample was filtered through a $0.45 \mu \mathrm{m}$ cellulose acetate filter. HPLC analysis of ascorbic acid
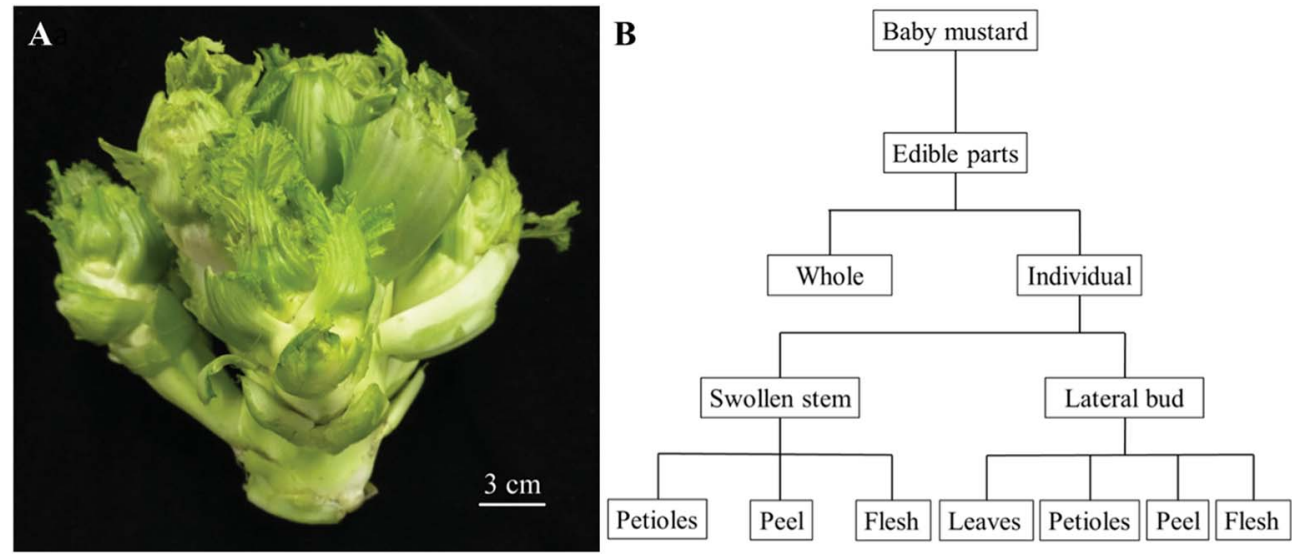

Fig. 1 The edible parts of baby mustard. (A) The whole edible parts; (B) the division of the edible parts. 
was carried out using a Waters instrument with a Model 2996 PDA detector (Waters Inc., Milford, USA). Sample $(20 \mu \mathrm{L})$ were separated at room temperature on a Waters Spherisorb C18 column $(150 \times 4.6 \mathrm{~mm}$ id; $5 \mu \mathrm{m}$ particle size $)$, using a solvent of $0.1 \%$ oxalic acid at a flow rate of $1.0 \mathrm{~mL} \mathrm{~min}{ }^{-1}$. The amount of ascorbic acid was calculated from absorbance values at $243 \mathrm{~nm}$, using authentic ascorbic acid as a standard. The results were expressed as $\mathrm{mg} \mathrm{g}^{-1}$ dry weight.

Proanthocyanidin content. Proanthocyanidin content was determined according to the method described by Prior et al. ${ }^{20}$ Forty milligrams of the lyophilized powder was transferred to $4 \mathrm{~mL}$ of the extracting reagent (acetone : distilled water : acetic acid $=150: 49: 1, \mathrm{v} / \mathrm{v}$ ). The solution was vigorously vortexed for $5 \mathrm{~min}$, shaken for $1 \mathrm{~h}$, and then centrifuged at $4000 \mathrm{~g}$ for $5 \mathrm{~min}$. Subsequently, $2.1 \mathrm{~mL} \quad p$-dimethylaminocinnamaldehyde (DMACA) reagent was added to $700 \mu \mathrm{L}$ of supernatant. The absorbance of the mixture was spectrophotometrically detected at $640 \mathrm{~nm}$ after $20 \mathrm{~min}$, and the proanthocyanidin content was determined using a standard curve of procyanidin B2.

Flavonoid content. Forty milligrams of sample powder was extracted in 50\% ethanol and incubated at room temperature for $24 \mathrm{~h}$ in the dark. The suspension was then centrifuged at $4000 \mathrm{~g}$ for $5 \mathrm{~min}$ at room temperature. A $1.2 \mathrm{~mL}$ aliquot of the supernatant was mixed with $60 \mu \mathrm{L} 2 \%$ aluminum trichloride, the same volume $(60 \mu \mathrm{L})$ of $1 \mathrm{~mol} \mathrm{~L}^{-1}$ potassium acetate, and $1.680 \mathrm{~mL}$ distilled water. Absorption was read at $415 \mathrm{~nm}$ after $40 \mathrm{~min}$. The flavonoid content was determined using a standard calibration curve with quercetin in $50 \%$ ethanol as a reference standard and expressed as mg of quercetin equivalence per $\mathrm{g}$ dry weight. ${ }^{21}$

Total phenolic content. Total phenolics were extracted with $50 \%$ ethanol and incubated at room temperature for $24 \mathrm{~h}$ in the dark. The suspension was centrifuged at $4000 \mathrm{~g}$ for $5 \mathrm{~min}$ at room temperature. The supernatant $(300 \mu \mathrm{L})$ was mixed with $1.5 \mathrm{~mL} 0.2 \mathrm{~mol} \mathrm{~L}^{-1}$ Folin-Ciocalteu reagent in a polypropylene tube, after $3 \mathrm{~min}, 1.2 \mathrm{~mL}$ saturated sodium carbonate was added to each polypropylene tube. The mixtures were allowed to stand for $20 \mathrm{~min}$ at room temperature and the absorbance was measured at $760 \mathrm{~nm}$ with the spectrophotometer as previously described..$^{22}$ Gallic acid was used as a standard and the results were expressed as $\mathrm{mg}$ garlic acid equivalent (GAE) per g dry weight.

Ferric reducing antioxidant power (FRAP). FRAP assay was performed according to the method of Benzie and Strain. ${ }^{23}$ The working FRAP reagent was prepared daily by mixing $300 \mathrm{mmol}$ $\mathrm{L}^{-1}$ acetate buffer ( $\left.\mathrm{pH} 3.6\right), 20 \mathrm{mmol} \mathrm{L}^{-1}$ ferric chloride, and $10 \mathrm{mmol} \mathrm{L}^{-1}$ 2,4,6-tripyridyl-S-triazine in $40 \mathrm{mmol} \mathrm{L}^{-1} \mathrm{HCl}$ in the ratio of $10: 1: 1(\mathrm{v} / \mathrm{v} / \mathrm{v})$. The extracted samples $(300 \mu \mathrm{L})$ were added to $2.7 \mathrm{~mL}$ of the FRAP working solution incubated at $37{ }^{\circ} \mathrm{C}$ and vortexed. The absorbance was then recorded at $593 \mathrm{~nm}$ using a UV-Vis spectrophotometer after the mixture had been incubated in at $37{ }^{\circ} \mathrm{C}$ for $10 \mathrm{~min}$. FRAP values were calculated based on $\mathrm{FeSO}_{4} \cdot 7 \mathrm{H}_{2} \mathrm{O}$ standard curves and expressed as $\mathrm{mmol} \mathrm{g}^{-1}$ dry weight.

2,2-Azinobis(3-ethyl-benzothiazoline-6-sulfonic acid) (ABTS). ABTS antioxidant activity was performed according to the method of Subhasree et al. ${ }^{24}$ The radicals $\mathrm{ABTS}^{+}$were generated by the addition of $2.45 \mathrm{mmol} \mathrm{\textrm {L } ^ { - 1 }}$ ammonium persulfate to a $7 \mathrm{mM}$ ABTS solution, and the $\mathrm{ABTS}^{+}$solution was stored in darkness for $16 \mathrm{~h}$. The $\mathrm{ABTS}^{+}$solution was adjusted with acetate buffer ( $\mathrm{pH} 4.5)$ to an absorbance of $0.700( \pm 0.020)$ at $734 \mathrm{~nm}$. An aliquot of $300 \mu \mathrm{L}$ of each extracted sample was added to $3 \mathrm{~mL}$ of $\mathrm{ABTS}^{+}$solution. The absorbance was measured spectrophotometrically at $734 \mathrm{~nm}$ after exactly $2 \mathrm{~h}$. The percentage inhibition was calculated according to the formula: $\%$ inhibition $=$ $\left[\left(A_{\text {control }}-A_{\text {sample }}\right) / A_{\text {control }}\right] \times 100 \%$.

\section{Statistical analysis}

All assays were performed in quadruplicate. The results are shown as the mean \pm standard deviation (SD). Statistical analysis was performed using the SPSS package program version 18 (SPSS Inc., Chicago, IL, USA). Data were analyzed using one-way analysis of variance (ANOVA). The means were compared using the Least Significant Differences (LSD) test at a significance level of 0.05. Hierarchical clustering analysis (HCA) and correlation analysis by means of a heatmap were generated using TIGR MeV software (Version 4.1). Principal component analysis (PCA) and partial least squares-discriminant analysis (PLS-DA) were performed in SIMCA-P 11.5 Demo software (Umetrics, Sweden) with unit variance (UV)-scaling to decipher the relationships among samples. ${ }^{25}$

\section{Results}

\section{Glucosinolates}

Unsurprisingly, all the individual baby mustard parts contained glucosinolates. Four indole (4-hydroxy glucobrassicin, glucobrassicin, 4-methoxyglucobrassicin, and neoglucobrassicin), three aliphatic (sinigrin, glucoalyssin, and gluconapin), and one aromatic (gluconasturtiin) glucosinolates were detected by High-Performance Liquid Chromatography (HPLC). There were remarkable differences in the glucosinolate composition and content among the individual edible parts of baby mustard. The total glucosinolate content of the edible parts ranged from 6.09 $\mu \mathrm{mol} \mathrm{g}{ }^{-1}$ in the swollen stem petioles to $33.60 \mu \mathrm{mol} \mathrm{g}^{-1}$ in the lateral bud peel. The total glucosinolate content of whole baby mustard was $18.11 \mu \mathrm{mol} \mathrm{g}^{-1}$. Aliphatic glucosinolates were the main contributor, contributing $90.78 \%$ of the glucosinolates in the whole edible parts, followed by indole glucosinolates $(7.62 \%)$ and aromatic glucosinolates $(1.55 \%)$. Among all of the glucosinolates, sinigrin was the major glucosinolate and accounted for $87.30 \%$ of the whole edible parts. A similar distribution was observed in the individual edible parts. In addition, among the edible parts, eight glucosinolates were detected in the lateral bud peel and lateral bud flesh; seven glucosinolates were detected in the swollen stem petioles, swollen stem peel, and lateral bud petioles; and five glucosinolates were observed in the lateral bud leaves. In contrast, only three glucosinolates were identified in the swollen stem flesh, including one indole, one aliphatic, and one aromatic glucosinolate. It should be noted that glucoalyssin was identified in all of the four parts of the lateral bud, but were not detected in the swollen stem. Excepting the lateral bud leaves, the distribution 


\section{- 0 웅}

न

$\begin{array}{llll}0 & 0 & 0 & 0 \\ H & + & H\end{array}$

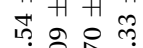

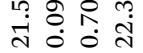

ส

ㄱํำ 둥 ㅇำ

0 000

$\mathrm{H} H \mathrm{H} H \mathrm{H}$

ํำ

둥

के

$H+{ }_{\infty}^{H}$

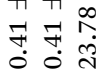

$\pi 0 \pi \pi$

ติำ

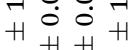

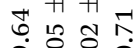

过芳

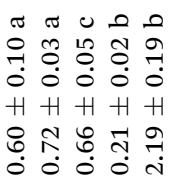

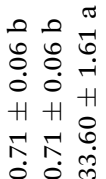

० 20

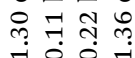

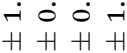

0 in 07

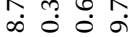

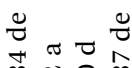

东

$\begin{array}{llll}0 & 0 & 0 & 0 \\ H & H & H\end{array}$

당

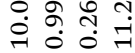

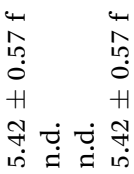

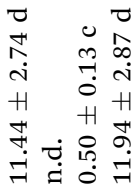

0

i

অ

กั ๑兀

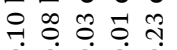

$\dot{0} \dot{0} \dot{0} \dot{0}$

$\mathrm{H} H+\mathrm{H} H$

늑 ㄴํำ ำ

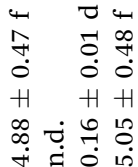

○ U

$\begin{array}{lllll}0 & 0 & \Re & -1 & 0 \\ 0 & 0 & 0 \\ 0 & 0 & 0 & 0 & 0 \\ 0 & 0 & 0\end{array}$

H H H H H

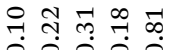

$\begin{array}{llll}0 & 0 & 0 & 0 \\ 0 & 0 & 0 & 0\end{array}$

œ

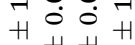

$-\mathrm{H}+\mathrm{H}$

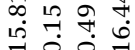

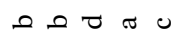

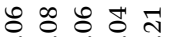

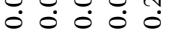

H H H H H

ते हี ले ते

०० 0 :

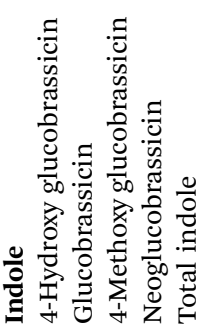

윰

热

007

$\mathrm{H}+\mathrm{H}$

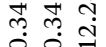$$
\text { ००न }
$$

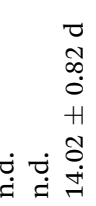

घ

00
0

ชิ ชิ เి

$\mathrm{H}+\mathrm{H}$

เก็น เก

000

* $\approx 0$

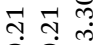

$\circ 0 \mathrm{H}$

H H H

ดे ڤํ

- 00

$\begin{array}{lll}m & m & \infty \\ 0 & 0 & 1 \\ 0 & 0 & 0 \\ 0\end{array}$

H H H

กิ กิ คำ

000 क

$\approx 00$

:

H $\mathrm{H} H$

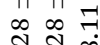

กุ

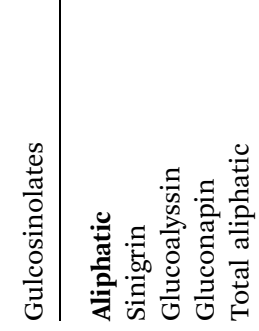

of glucosinolates in the swollen stem and lateral bud was concordant. The peel had the highest glucosinolate content, followed by the flesh and petioles whether in the swollen stem or lateral bud. Furthermore, for the same tissue, the contents of total glucosinolates in the lateral bud were significantly higher than in the swollen stem (Table 1).

\section{Soluble proteins and soluble sugars}

The composition and content of the main nutrients and healthpromoting compounds in baby mustard are shown in Table 2 . The soluble protein content in the seven individual edible parts ranged from $38.81 \mathrm{mg} \mathrm{g}^{-1}$ to $91.10 \mathrm{mg} \mathrm{g}^{-1}$. Overall, the soluble protein content was highest in the lateral bud leaves, followed by the lateral bud petioles, and was lowest in the swollen stem petioles. The soluble proteins in the flesh were highest, followed by the peel and then the petioles in the swollen stem, while an opposite pattern was observed in the lateral bud. A comparison of the seven edible parts with the entire baby mustard plant indicated that the lateral bud leaves, petioles, and peel were higher in soluble protein than the whole plant, while the other parts were lower in soluble protein content.

The soluble sugar contents ranged between $155.31 \mathrm{mg} \mathrm{g}^{-1}$ in the lateral bud leaves and $463.85 \mathrm{mg} \mathrm{g}^{-1}$ in the lateral bud flesh. The difference among the samples was nearly three-fold. The soluble sugar content of the petioles was highest in the swollen stem, whereas the flesh in the lateral bud had the highest soluble sugar content. Of the edible parts, only the lateral bud flesh was higher in comparison to the whole parts (Table 2).

\section{Chlorophylls and carotenoids}

Chlorophyll content ranged from $10.71 \mathrm{mg} \mathrm{kg}^{-1}$ in the swollen stem flesh to $3345.13 \mathrm{mg} \mathrm{kg}{ }^{-1}$ in the lateral bud leaves. A similar distribution was observed with the carotenoid content in the various edible parts. The carotenoid content ranged from $0.88 \mathrm{mg} \mathrm{kg}^{-1}$ in the swollen stem flesh to $335.02 \mathrm{mg} \mathrm{kg}^{-1}$ in the lateral bud leaves. Thus, the chlorophyll and carotenoid contents in the lateral bud leaves were generally more than 300 times greater than those in the swollen stem flesh (Table 2).

\section{Ascorbic acid}

The ascorbic acid content was lowest in the swollen stem peel (2.59 $\mathrm{mg} \mathrm{g}^{-1}$ ) and highest in the lateral bud petioles $(5.11 \mathrm{mg}$ $\left.\mathrm{g}^{-1}\right)$. In the swollen stem, the ascorbic acid content in the flesh was highest, followed by the petioles and the peel. In the lateral bud, the petioles had the highest content of ascorbic acid, followed by the leaves, flesh, and peel (Table 2).

\section{Proanthocyanidins, flavonoids, and total phenolics}

There were significant differences in the contents of proanthocyanidins, flavonoids, and total phenolics among the different edible parts. The highest content of proanthocyanidins, flavonoids, and total phenolics were observed in the lateral bud leaves $\left(3.35 \mathrm{mg} \mathrm{g}^{-1}, 19.30 \mathrm{mg} \mathrm{g}^{-1}\right.$, and $17.66 \mathrm{mg} \mathrm{g}^{-1}$, respectively). The lowest proanthocyanidin content was recorded in the swollen stem flesh $\left(0.20 \mathrm{mg} \mathrm{g}^{-1}\right)$. However, the lowest 
ช 군 0 교요 $\mathrm{H} H \mathrm{H} H \mathrm{H} H \mathrm{H} H$

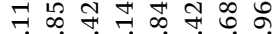
லि

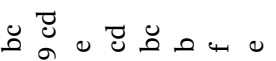

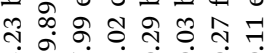
$H+H+H+H H$

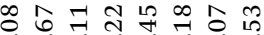

i⿱

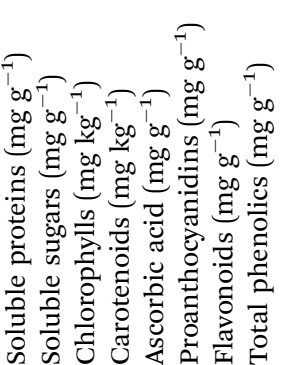

contents of flavonoids and total phenolics were both detected in the swollen stem peel $\left(1.84 \mathrm{mg} \mathrm{g}^{-1}\right.$ and $1.96 \mathrm{mg} \mathrm{g}^{-1}$, respectively). With the exception of the lateral bud leaves, the distribution of flavonoids in the swollen stem and lateral bud was concordant. The flesh contained the highest flavonoid content, followed by the petioles and peel whether in the swollen stem or lateral bud. Furthermore, the lowest proanthocyanidin content was detected in the flesh, regardless of whether it was the swollen stem or lateral bud. However, no significant difference in proanthocyanidin content was found between the petioles and peel. Nevertheless, the distribution of total phenolics in the swollen stem and lateral bud among the petioles, peel, and flesh differed. The highest total phenolic content in the swollen stem was detected in the flesh, followed by the petioles and the peel. In contrast, in the lateral bud, the phenolic content in the petioles was higher than in the flesh, while the peel still contained the lowest content of total phenolics (Table 2).

\section{Antioxidant activity}

The results obtained for the antioxidant activity based on the FRAP and ABTS assays are displayed in Fig. 2. Significant differences were observed in the individual edible parts. The highest FRAP and ABTS values $\left(121.17 \mathrm{mmol} \mathrm{kg}^{-1}\right.$ and $69.59 \%$, respectively) were measured in the lateral bud leaves. The swollen stem peel was characterized by the lowest FRAP and ABTS activities (33.92 $\mathrm{mmol} \mathrm{kg}^{-1}$ and $19.90 \%$, respectively). The antioxidant activity of the flesh was significantly higher than the peel in both the swollen stem and lateral bud. Additionally, the antioxidant activities of the swollen stem petioles, peel, and lateral bud peel were significantly lower than the whole edible parts, while those of the remaining parts were higher.

\section{HCA}

HCA of the whole and individual edible parts was performed to visualize the main health-promoting compounds and antioxidant activities (Fig. 3). To determine the relationships and trends of these different parts, the heatmap was divided into

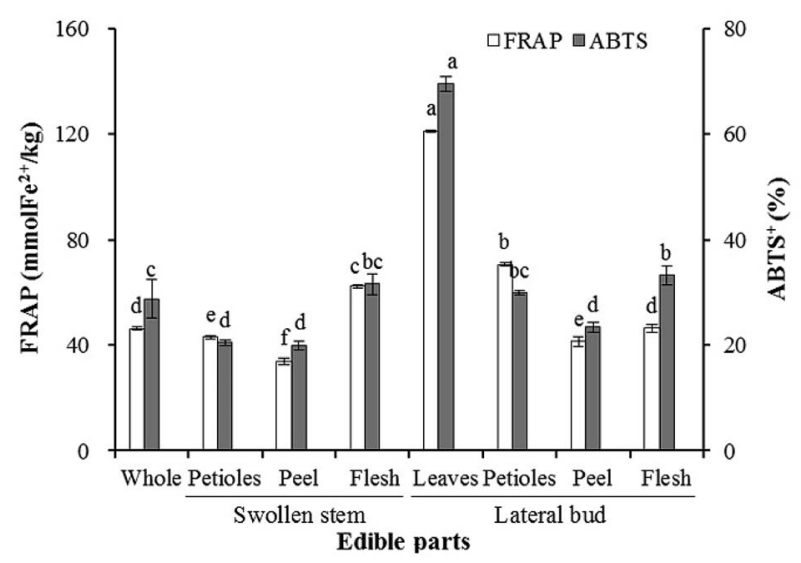

Fig. 2 Antioxidant activities in the whole and individual edible parts of baby mustard. Standard deviations are expressed by bars. For each tissue, same letter in the same testing method means no significant differences $(p<0.05)$ according to the LSD's test. 


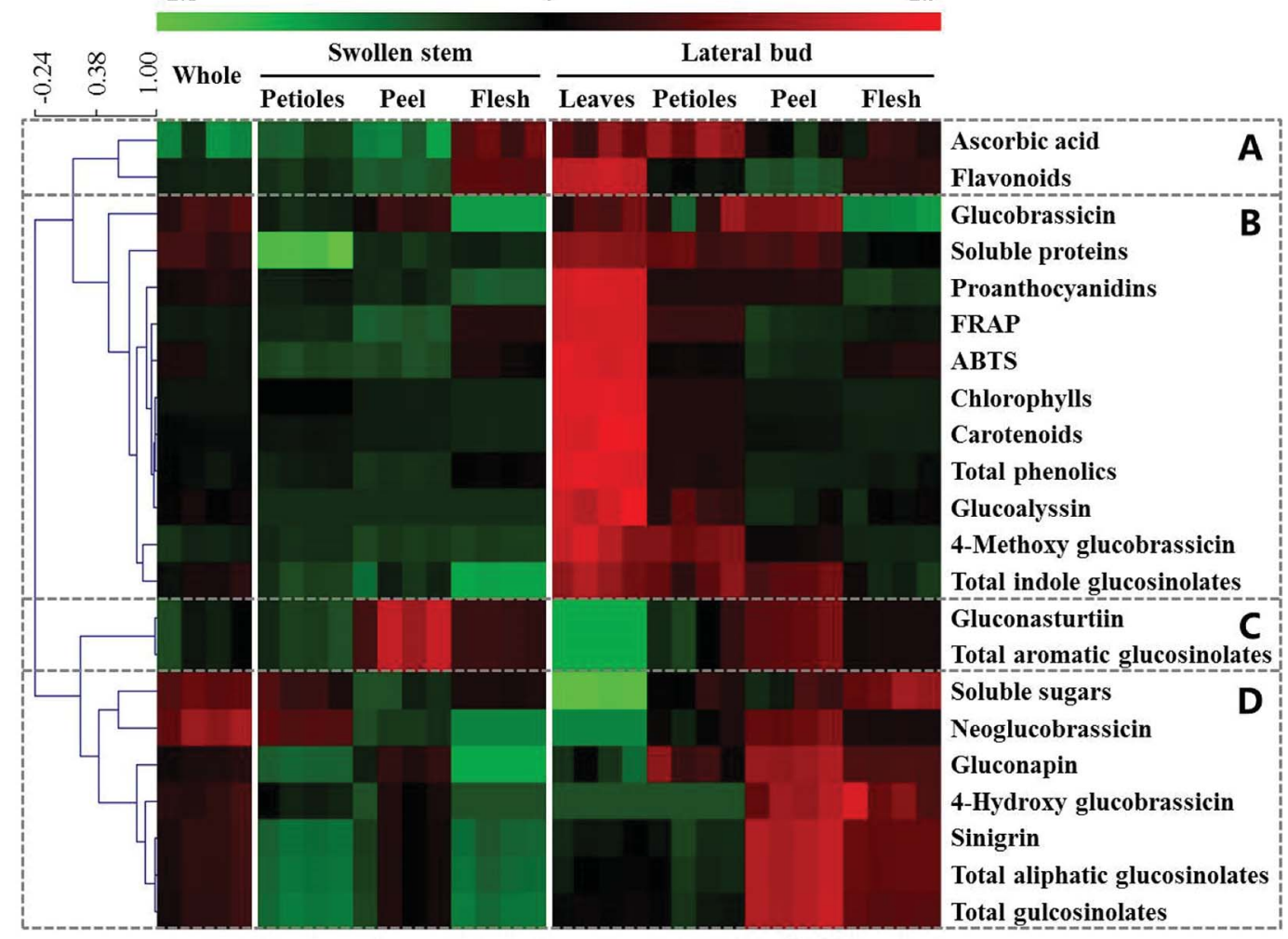

Fig. 3 Heatmap and HCA of the main health-promoting compounds and antioxidant activities in whole and individual parts of baby mustard. Green and red reflect the relative concentrations.

four groups. Group A only contained ascorbic acid and flavonoids, which were highest in the lateral bud leaves and relatively high in the flesh of the swollen stem and the lateral bud. Group B is the largest group in Fig. 3 and contained antioxidant activities and most of the health-promoting compounds. The lateral bud leaves were highest in these indices. Group C included gluconasturtiin, a type of aromatic glucosinolate, and total aromatic glucosinolates, which were highest in the peel whether in the swollen stem or lateral bud. Sinigrin, the principal contributor of total aliphatic glucosinolates and total glucosinolates, together with soluble sugars and several other glucosinolates, was located in group D. These were most highly expressed in the peel and flesh of the lateral bud.

\section{PCA}

PCA was performed to compare the distribution of the main health-promoting compounds and antioxidant activity among the whole and individual parts of baby mustard. As shown in Fig. 4 , the first component accounted for $52 \%$, while the second component represented $26 \%$. The whole edible part samples grouped close to the origin. The leaves and petioles of the lateral bud could be discriminated from the other parts by PC1. Additionally, the swollen stem could be discriminated from the lateral bud by PC2 (Fig. 4A). The results of the PCA and PLS-DA were congruent and indicated that the whole edible parts were similar to the lateral bud flesh in terms of the measured constituents, which is to be expected as the lateral bud flesh is the primary edible part in baby mustard (Fig. 4B). Fig. 4C shows that PC1 was dominated by total phenolics, FRAP, chlorophylls, carotenoids, glucoalyssin, ABTS, proanthocyanidins, 4-methoxy glucobrassicin, flavonoids, soluble sugars, gluconasturtiin, and total aromatic glucosinolates. In contrast, PC2 was dominated by total glucosinolates, total aliphatic glucosinolates, sinigrin, gluconapin, and flavonoids. The lateral bud leaves and other parts were primarily discriminated based on chlorophylls, carotenoids, total phenolics, FRAP, ABTS, glucoalyssin, 4methoxy glucobrassicin, and proanthocyanidins. In contrast, gluconapin, sinigrin, total aliphatic glucosinolates, and total glucosinolates play an important role in the lateral peel.

\section{Correlation analysis}

The correlation between the health-promoting compounds and antioxidant activity was expressed as a heatmap (Fig. 5). Correlation analysis indicated two significantly positively correlated connections between the variables. The first was the correlation between glucobrassicin, ascorbic acid, flavonoids, FRAP, ABTS, chlorophylls, carotenoids, total phenolics, glucoalyssin, proanthocyanidins, 4-methoxy glucobrassicin, soluble proteins, and total indole glucosinolates, and the second was the association between gluconasturtiin, total aromatic glucosinolates, soluble sugars, neoglucobrassicin, 4hydroxy glucobrassicin, gluconapin, sinigrin, total aliphatic glucosinolates, and total glucosinolates, with the exception that gluconasturtiin and total aromatic glucosinolates were not 

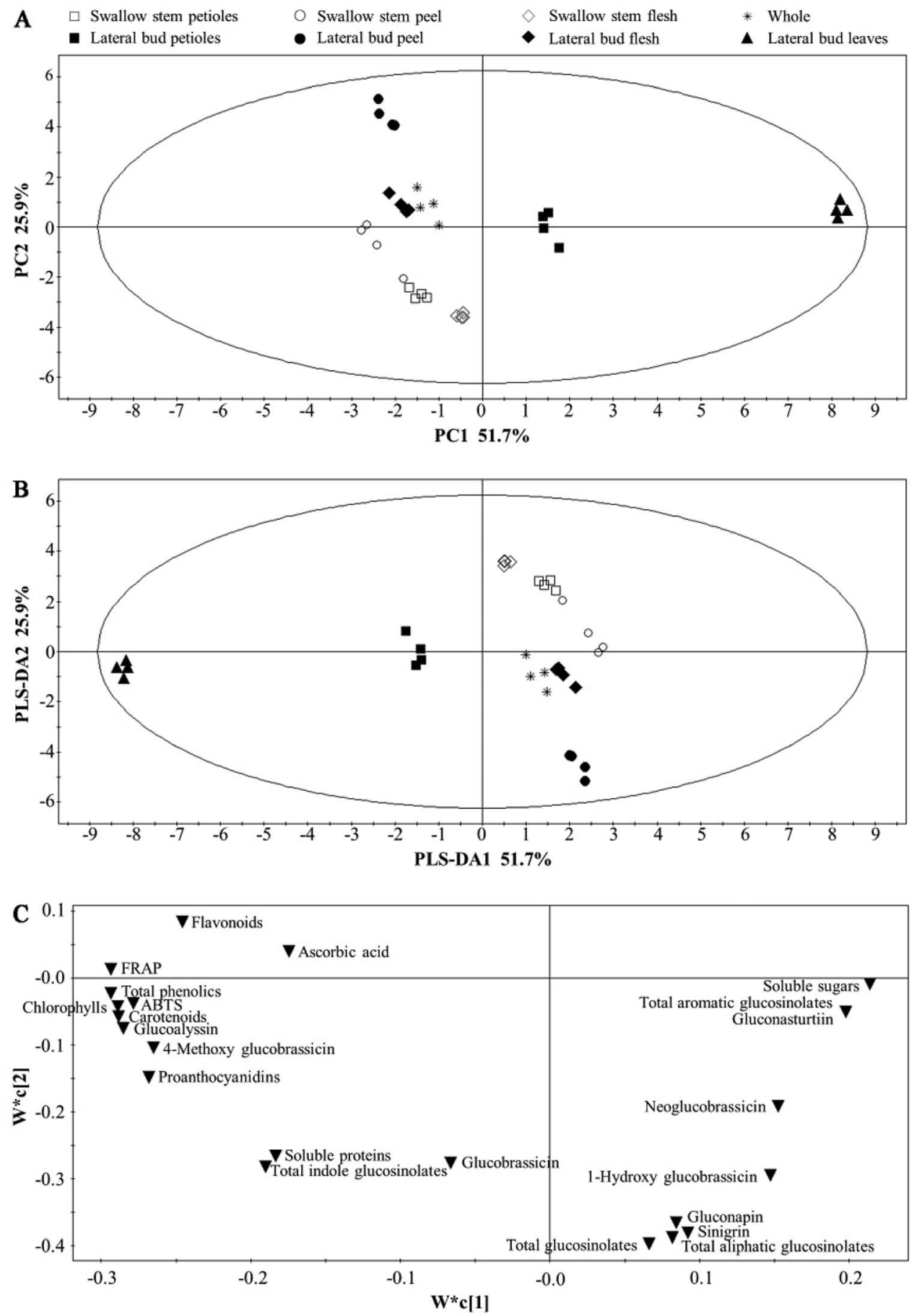

Fig. 4 PCA and PLS-DA analysis of whole and individual parts of baby mustard. (A) PCA score plot; (B) PLS-DA score plot; (C) PLS-DA loading plot.

correlated with soluble sugars and neoglucobrassicin. However, most of the variables between the first group and second group were negatively correlated with each other. In addition, the positive correlations between chlorophylls and carotenoids, as well as among sinigrin, total aliphatic glucosinolates, and total glucosinolates, were highest, while the greatest negative correlations were observed between gluconasturtiin, total aromatic glucosinolates, soluble sugars and flavonoids, FRAP, ABTS, chlorophylls, carotenoids, total phenolics, glucoalyssin, proanthocyanidins, and 4-methoxy glucobrassicin.
The ABTS and FRAP results were consistent with each other. The correlation analysis indicated that antioxidant activity was positively associated with ascorbic acid, chlorophylls, carotenoids, total phenolics, flavonoids, glucoalyssin, proanthocyanidins, 4-methoxy glucobrassicin, soluble proteins, and total indole glucosinolates. Specifically, the correlation with total phenolics was highest, whereas the remaining components were negatively correlated, with the exception of glucobrassicin. Glucosinolates could be divided into three parts based on the correlation analysis. The first part contained glucoalyssin, 


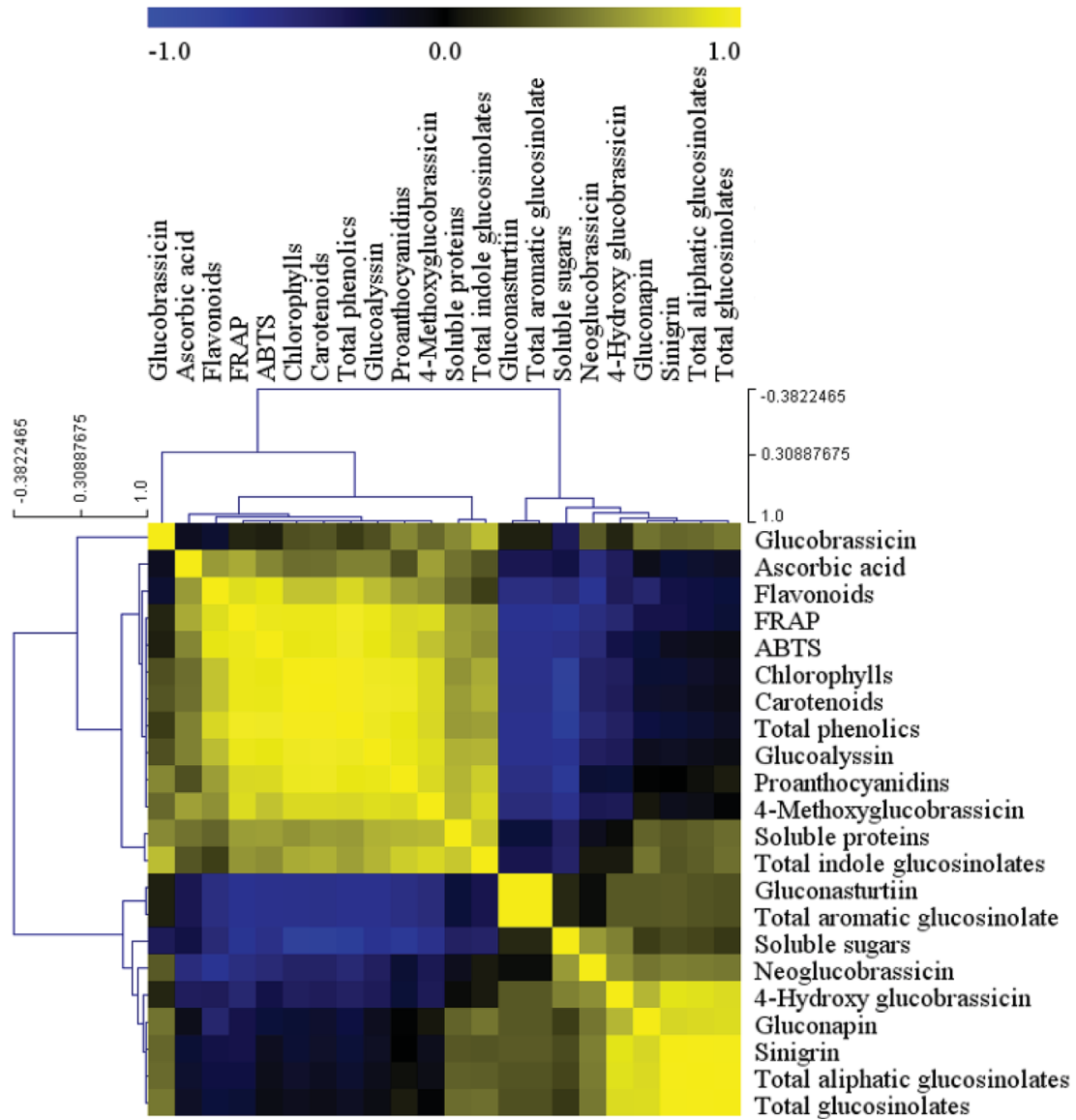

Fig. 5 Correlation analysis among the main health-promoting compounds and antioxidant activity in baby mustard. Yellow indicates a positive correlation, black intermediate no relevance, and blue indicates a negative correlation.

which was positively correlated with 4-methoxy glucobrassicin, both of which were negatively correlated with gluconasturtiin, total aromatic glucosinolates, neoglucobrassicin, and 4-hydroxy glucobrassicin. The second part contained gluconasturtiin, which was highly positively correlated with total aromatic glucosinolates. The third part contained neoglucobrassicin, 4hydroxy glucobrassicin, sinigrin, total aliphatic glucosinolates, and total glucosinolates, all of which were positively correlated with one another.

\section{Discussion}

The present study is the first to comprehensively assess the primary health-promoting compounds, identify the glucosinolate compositions, and evaluate the antioxidant activities of the whole and individual edible parts of baby mustard. Our results showed that significant differences existed among the different individual edible parts, and the nutritional value of the lateral bud was higher than the swollen stem. Eight glucosinolates were detected, and sinigrin was found to be the major glucosinolate.

Many studies have indicated that significant differences exist among different plant organs/tissues in terms of nutritional composition and content. ${ }^{26,27}$ Generally, the leaves are more nutritious than the petioles, roots, and other organs. ${ }^{28}$ Our results are consistent with this, except with regards to the ascorbic acid and soluble sugar contents. In our study, the content of ascorbic acid in the flesh was higher than the peel, which corroborates a previous study. ${ }^{25}$ Interestingly, the soluble protein, chlorophyll, carotenoid, proanthocyanidin, and majority of glucosinolate contents in the lateral bud were higher than in the swollen stem in the corresponding tissues, which might be explained by the source-sink theory.

Glucosinolates and their breakdown products are beneficial to human health. Several studies have suggested that aliphatic glucosinolates constitute a predominant component of total glucosinolates in Brassica. ${ }^{29-31}$ In this study, aliphatic glucosinolates accounted for almost $90 \%$ of the whole edible parts of baby mustard. Additionally, the glucosinolate composition and content in the different edible parts differed significantly in our study, which corroborates the results of Maldini et al. ${ }^{32}$ and Sun et $a l^{16}$ Furthermore, the content of aromatic glucosinolates in the peel was higher than the other edible parts of baby mustard. Considering that the peel constitutes the protective screen of plants, we inferred that the high content of aromatic glucosinolates in the peel protects the plants by resisting disease and pathogens. ${ }^{33}$

Many studies have confirmed that glucosinolate compositions differ among distinct species. The most abundant glucosinolate in mustard is sinigrin, ${ }^{34}$ while in broccoli it is glucoraphanin; ${ }^{17}$ in Chinese kale it is gluconapin; ${ }^{16}$ in loose- 
curd cauliflower it is glucoiberin; ${ }^{35}$ in cabbage it is glucobrassicin; and in the different tissues of wild radish it is glucoraphanin and glucoraphasatin. ${ }^{32}$ However, glucosinolate compositions are typically similar in the same species. Seven types of glucosinolates have previously been detected in Indian mustard ${ }^{36}$ nine have been detected in tuber mustard, and eight were detected in baby mustard in the present study. In our study, the content of sinigrin in the various tissues of the edible parts of baby mustard accounted for about $70 \%$ to $90 \%$ of the total glucosinolate composition. Sinigrin is also the dominant glucosinolate in tuber mustard. However, there was a slight difference in aliphatic glucosinolate composition between baby mustard and tuber mustard, whereas the composition of other glucosinolates was the same. ${ }^{37}$ Sinigrin was found to be one of the most important glucosinolates influencing the flavor of cruciferous plants, and is an important component of pungency in mustard. However, the sinigrin content in baby mustard

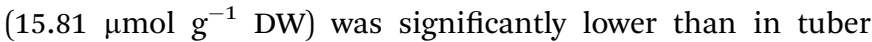

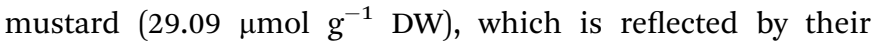
different uses in the everyday human diet. Tuber mustard is typically made into preserved Szechuan pickle by the people of Southwest China, the unique flavor of which is mainly attributed to the abundant glucosinolate hydrolysates. Baby mustard has been artificially bred for its low glucosinolate content, and particularly its sinigrin content, which renders the flavor of baby mustard less pungent and more suitable for being eaten fresh.

Antioxidant activity between different plant organs/tissues generally differs significantly. ${ }^{38,39}$ Our results also indicated that the leaves, petioles, peel, and flesh of the edible parts of baby mustard exhibited good and distinct antioxidant activity as determined by ABTS and FRAP, and the tissue with the highest antioxidant activity was the leaves, while the swollen stem peel had the lowest activity. The antioxidant activity of the peel in tuber mustard and bamboo shoots mustard is higher than the flesh, ${ }^{25}$ and similar results have been found in apple. ${ }^{40}$ However, in our study, the antioxidant activity of the peel and flesh in baby mustard exhibited a contrary pattern. Antioxidant activity is correlated with total phenolic content in many studies, ${ }^{41}$ and the total phenolic content in the flesh was also higher than in the peel in baby mustard.

Gluconasturtiin, soluble sugars, and many antioxidants were negatively correlated, whereas gluconasturtiin and soluble sugars did not exhibit any correlation. Interestingly, glucosinolates, soluble sugars, and antioxidant activity are all closely associated with stress resistance in plants..$^{3,42,43}$ Usually, the soluble sugar content will increase and plant growth will decline when plants are subjected to adverse situations. We inferred that soluble sugars, as the primary energy material, respond to stress by increasing the osmotic pressure in plants, thus resulting in growth suppression. As the situation becomes more serious, the soluble sugar content will increase accordingly. However, the high level of antioxidant activity will be beneficial for reducing injury in plants, and thus the soluble sugar content will decrease. Glucosinolate metabolites are one of the most predominant defense and immunity components in plants. It has been reported that glucosinolates will interact with each other to maintain cellular homeostasis in plants. ${ }^{44}$ In our study, glucoalyssin and 4-methoxy glucobrassicin demonstrated a synergistic interaction, and both were negatively correlated with gluconasturtiin.

\section{Conclusions}

This is the first report on the content and composition of health-promoting compounds, glucosinolates, and antioxidant activity in the whole and individual edible parts of baby mustard. The contents of these significantly differed among the whole and individual parts. Glucosinolate content was highest in the lateral bud peel in comparison to the other parts. The lateral bud had higher nutritional value than the swollen stem. In addition, the lateral bud leaves contained high levels of antioxidants and antioxidant activity, and thus should be conserved during harvesting for their health-promoting properties. Besides tissues, varieties and developmental stages also have a significant influence on health-promoting compounds, which will be explored in further study. In summary, the information in this study provides a theoretical reference for human dietary nutrition and a foundation for the further study of baby mustard.

\section{Conflicts of interest}

The authors declare no conflict of interest.

\section{Acknowledgements}

This work was supported by National Natural Science Foundation of China (31500247), Key Project of Department of Education of Sichuan Province (14ZA0016), and National Student Innovation Training Program (201710626030). We thank Accdon for its linguistic assistance during the preparation of this manuscript.

\section{References}

1 E. Ciska, N. Drabińska, A. Narwojsz and J. Honke, Food Chem., 2016, 203, 340-347.

2 B. L. Petersen, S. Chen, C. H. Hansen, C. E. Olsen and B. A. Halkier, Planta, 2002, 214, 562-571.

3 R. Verkerk, M. Schreiner, A. Krumbein, E. Ciska, B. Holst, I. Rowland, R. De Schrijver, M. Hansen, C. Gerhäuser, R. Mithen and M. Dekker, Mol. Nutr. Food Res., 2009, 53, S219.

4 N. Agerbirk and C. E. Olsen, Phytochemistry, 2015, 115, 143151.

5 R. Agneta, F. Lelario, S. D. Maria, C. Möllers, S. A. Bufo and A. R. Rivelli, Phytochemistry, 2014, 106, 178-187.

6 G. Yuan, B. Sun, J. Yuan and Q. Wang, Food Chem., 2010, 118, 774-781.

7 G. Padilla, M. E. Cartea, P. Velasco, A. Haro and A. Ordás, Phytochemistry, 2007, 68, 536-545.

8 I. E. Sønderby, F. Geu-Flores and B. A. Halkier, Trends Plant Sci., 2010, 15, 283-290. 
9 A. T. Dinkova-Kostova and R. V. Kostov, Trends Plant Sci., 2012, 18, 337-347.

10 X. Jin, T. Oliviero, R. G. M. van der Sman, R. Verkerk, M. Dekker and A. J. B. van Boxtel, LWT-Food Sci. Technol., 2014, 59, 189-195.

11 S. Park, M. V. Arasu, M. K. Lee, J. H. Chun, J. M. Seo, S. W. Lee, N. A. Al-Dhabi and S. J. Kim, Food Chem., 2014, 145, 77-85.

12 A. P. Vale, J. Santos, N. V. Brito, V. Peixoto, R. Carvalho, E. Rosa and M. B. P. P. Olierira, Food Chem., 2015, 178, 292-300.

13 B. Sun, H. Yan, F. Zhang and Q. Wang, Food Res. Int., 2012, 48, 359-366.

14 Y. Lin and S. X. Li, Acta Hortic. Sin., 1985, 12, 41-44.

15 W. M. Jin, S. Y. Zou, W. S. Peng and S. Z. Mai, J. Shanghai Agric. Coll., 1999, 17, 123-126.

16 B. Sun, N. Liu, Y. Zhao, H. Yan and Q. Wang, Food Chem., 2011, 124, 941-947.

17 J. Wang, H. Gu, H. Yu, Z. Zhao, X. Sheng and X. Zhang, Food Chem., 2012, 133, 735-741.

18 M. M. Bradford, Anal. Biochem., 1976, 72, 248-254.

19 D. L. Morris, Science, 1948, 107, 254-255.

20 R. L. Prior, E. Fan, H. Ji, A. Howell, C. Nio, M. J. Payne and J. Reed, J. Sci. Food Agric., 2010, 90, 1473-1478.

21 C. C. Chang, M. H. Yang, H. M. Wen and J. C. Chern, J. Food Drug Anal., 2002, 10, 178-182.

22 E. A. Ainsworth and K. M. Gillespie, Nat. Protoc., 2007, 2, 875-877.

23 I. F. Benzie and J. J. Strain, Anal. Biochem., 1996, 239, 70-76.

24 B. Subhasree, R. Baskar, R. L. Keerthana, R. L. Susan and P. Rajasekaran, Food Chem., 2009, 115, 1213-1220.

25 B. Sun, X. Xia, J. Gu, Y. Tian, F. Zhang, Q. Chen, Y. Hou, J. Ma and H. Tang, Acta Agric. Nucl. Sin., 2016, 30, 485-492.

26 S. C. Liu, J. T. Lin, C. C. Hu, B. Y. Shen, T. Y. Chen, Y. L. Chang, C. H. Shih and D. J. Yang, Food Chem., 2017, 215, 284-291.

27 I. M. Abu-Reidah, Á. Gil-Izquierdo, S. Medina and F. Ferreres, Food Res. Int., 2017, 100, 494-500.
28 E. A. Brisibe, U. E. Umoren, F. Brisibe, P. M. Magalhäes, J. F. S. Ferreira, D. Luthria, X. Wu and R. L. Prior, Food Chem., 2009, 115, 1240-1246.

29 H. S. Helland, A. Leufvén, G. B. Bengtsson, J. Skaret, P. Lea and A. Wold, Postharvest Biol. Technol., 2016, 111, 150-160.

30 H. Shi, Y. Zhao, J. Sun, L. Yu and P. Chen, J. Food Compos. Anal., 2017, 61, 67-72.

31 M. Thomas, A. Badr, Y. Desjardins, A. Gosselin and P. Angers, Food Chem., 2018, 245, 1204-1211.

32 M. Maldini, M. Foddai, F. Natella, G. L. Petretto, J. P. Rourke, M. Chessa and G. Pintore, J. Food Compos. Anal., 2017, 61, 20-27.

33 G. Brader, M. D. Mikkelsen, B. A. Halkier and E. T. Palva, Plant J., 2006, 46, 758-767.

34 V. M. Koritsas, J. A. Lewis and G. R. Fenwick, Ann. Appl. Biol., 1991, 118, 209-221.

35 J. Wang, Z. Zhao, X. Sheng, H. Yu and H. Gu, LWT-Food Sci. Technol., 2015, 61, 177-183.

36 M. V. Palmer, S. P. Yeung and J. P. Sang, J. Agric. Food Chem., 1987, 35, 262-265.

37 Y. Li, X. Wang, Y. Wang, Q. Meng, J. Sun and B. Wang, Acta Hortic. Sin., 2011, 38, 1356-1364.

38 J. Kubola and S. Siriamornpun, Food Chem., 2008, 110, 881890.

39 Z. Amri, F. Zaouay, H. Lazreg-Aref, H. Soltana, A. Mneri, M. Mars and M. Hammami, Int. J. Biol. Macromol., 2017, 104, 174-180.

40 F. G. K. Vieira, G. D. S. C. Borges, C. Copetti, P. F. D. Pietro, E. D. C. Nunes and R. Fett, Sci. Hortic., 2011, 128, 261-266.

41 M. Shiraishi, R. Shinomiya and H. Chijiwa, Sci. Hortic., 2018, 227, 272-277.

42 H. Sasaki, K. Ichimura, K. Okada and M. Oda, Sci. Hortic., 1998, 76, 161-169.

43 S. J. Yang, M. Hosokawa, Y. Mizuta, J. G. Yun, J. Mano and S. Yazawa, Sci. Hortic., 2001, 88, 59-69.

44 T. Gigolashvili, M. Engqvist, R. Yatusevich, C. Müller and U. Flügge, New Phytol., 2008, 177, 627-642. 